\title{
Low level of knowledge about neonatal danger signs and its associated factors among postnatal mothers attending at Woldia general hospital, Ethiopia
}

Mekdes Mengesha Jemberia', Elsa Tesfa Berhe', Hawi Bersisa Mirkena', Destaw Molla Gishen', Abera Endale Tegegne ${ }^{1}$ and Melese Abate Reta ${ }^{2^{*}}$

\begin{abstract}
Background: Neonatal mortality has persisted high in Ethiopia in spite of many efforts being applied to decrease this adverse trend. Early detection of neonatal illness is an important step towards improving newborn survival. Toward this end, there is a need for the mothers to be able to identify signs in neonates that signify severe illnesses. The aim of this study was to assess knowledge about neonatal danger signs and its associated factors among postnatal mothers attending at Woldia general hospital, Ethiopian.

Methods: Institutional based cross-sectional study design was conducted from January-May, 2017. The hospital that provides antenatal care (ANC), delivery, and postnatal services was purposively sampled. Structured interviewer managed questionnaire was administered to postnatal mothers attending Woldia general hospital. Frequencies, bivariate and multivariate logistic regression were determined using the SPSS software (Version 20).

Results: During the study period 197 mothers attending postnatal care (PNC) service at Woldia general hospital were interviewed. Information on different neonatal danger signs was not provided to 92(46.7\%) postnatal mothers during their antenatal clinic attendance by the healthcare providers. The majority of mothers, $174(88.3 \%)$ identified less than six neonatal danger signs. The hotness of the body of neonates was the commonly recognized danger sign by 106(53.8\%) postnatal mothers. Of the total mothers, 67(34\%), 60(30.5\%), 56(28.4\%), 44(22.3\%) recognized unable to breastfeeding, convulsion, lethargy, difficulty in breathing as newly born danger signs, respectively. Out of 197 mothers, 32(16.2\%) were giving birth at home. Mother's age(AOR $=1.33,95 \% \mathrm{Cl}: 1.99-3.08)$, marital status(AOR $=2$. 50, 95\% Cl: 0.29-4.31), mother's education status(AOR $=3.48,95 \%$ Cl:1.57-8.72), husband's education( $\mathrm{AOR}=4.92,95 \%$ Cl: 1.29-12.81), attending ANC (AOR $=2.88,95 \% \mathrm{Cl}: 1.15,4.85)$, mother's residence(AOR $=0.78,95 \%$ Cl: $0.47-1.65)$, information about neonatal danger signs( $\mathrm{AOR}=3.48,95 \% \mathrm{Cl} 1.40-9.49$ ) had positive association with maternal level of knowledge to identify different neonatal danger signs.
\end{abstract}

Conclusion: Maternal knowledge level about neonatal danger signs was very low. Therefore, intervention modalities that focus on increasing level of parental education, access to ANC and PNC service are needed.

Keywords: Knowledge, Neonates, Danger signs, Associated factors, Postnatal mothers, Woldia

\footnotetext{
* Correspondence: melese1985@gmail.com

${ }^{2}$ Department of Medical Laboratory Science, Faculty of Health Science,

Woldia University, P.O.Box 400, Woldia, Ethiopia

Full list of author information is available at the end of the article
} 


\section{Background}

The neonatal period is the first 4 weeks of life and represents a vulnerable time in an individual's life [1]. Early detection of neonatal illness through identifying neonatal danger signs is an important step towards improving newborn survival [2]. Globally, each year about 4 million children die in the first 28 days of life [3], and this accounts for $40 \%$ of the death of children under the age of 5 years globally [4]. Most neonatal death occurs in low-income and middle-income countries, particularly in Sub-Saharan Africa [3]. In Ethiopia, about 120,000 babies died at the first 4 weeks of life [5], and this neonatal mortality rate accounts for $42 \%$ of under- 5 deaths in the country $[5,6]$. The majority of this newborn death occurs at home (outside the formal health system) where only a few mothers and families recognize danger signs of newborn illness $[3,4]$. It is terrible that many of newborn die every year especially when their death is preventable. The risk of neonatal death is high in the first $24 \mathrm{~h}$ of life [5]. The causes of neonatal mortality are not well documented in Ethiopia, however, some studies reported causes such as sepsis, asphyxia, birth injury, tetanus, preterm birth, congenital malformations and unknown causes $[5,6]$. Some of the repeatedly reported neonatal danger signs include unable to breastfeed, the movement only when stimulated, low or high temperature, the respiratory rate over 60 breaths per minute, severe chest in drawing and history of convulsion [3]. Recognizing the occurrence of these signs will result in high overall sensitivity and specificity to predict the need for seeking treatment of the newborn $[3,7,8]$. It is estimated that about $75 \%$ of neonatal deaths can be avoided [3, 9]. However, this is only possible if mother's knowledge regarding the neonatal danger signs is good enough to make a decision to seek health care service [3], Because mother's poor knowledge about newborn danger signs delay cares to seek health care service and treatment [2]. According to a report by Nigatu et al., mothers and husbands higher educational achievement, ANC and PNC attendance and access to television for information were positively associated with mother's good knowledge about neonatal danger signs [3]. Okawa et al., reported that potential determinants of neonatal danger signs and factors that would delay for sick newborn treatment were categorized into four domains: maternal factors, family factors, antenatal factors, and delivery factors [10].

For the last era, neonatal deaths have gained attention on the global policy agenda because the Millennium Development Goal (MDG) for child survival cannot be met without substantial reductions in neonatal mortality. It is estimated that reduction of under- 5 child mortality by two-thirds by 2015 , as called for by the MDG, requires a reduction in neonatal mortality of at least $50 \%$ [6].
Different tools to facilitate identification of neonatal health problems and management were introduced into the health programs in several countries like Ethiopia. Integrated Management of Newborn and childhood illness developed by world health organization(WHO) was the one which focused on assessment of neonatal danger signs and applies prompt timely treatment [3, 11]. Similarly, Bhutta et al. report, early identification of newborn danger signs by caregivers with prompt and appropriate referral serves as backbone of the programs aiming at reduction in neonatal mortality [12]. According to a report by Yared et al., in Ethiopia, the neonatal mortality rate declined by $1.9 \%$ per annum from 1995 to 2010, logarithmically. The early neonatal mortality rate declined by $0.9 \%$ per annum and was where $74 \%$ of the neonatal deaths occurred [6]. According to 2016 EDHS report all childhood mortality rates have declined over time; the under-5 mortality rate has declined from 116 deaths per 1000 live births $10-14$ years prior to the survey (2002-2006) to 67deaths per 1000 live births in the 0-4 years prior to the survey (2012-2016); and the neonatal mortality rate was 29 deaths per 1000 live births [11].

Generally, reducing neonatal morbidity and mortality requires immediate caregiver's recognition of suggestive danger signs in the neonates and visiting the nearby clinic for early treatment. Trends in Ethiopian society so far recognized mothers as caretakers for the majority of neonates [3, 13]. Therefore, improving maternal knowledge concerning neonatal danger sign is a key entry point [3]. However, studies in the area are limited and inconsistent. Numerous studies have examined the determinants of neonatal mortality, but few have explored maternal levels of knowledge on neonatal danger signs and different danger signs which potentially cause neonatal morbidity [10]. Therefore, the main aim of this study was to explore the maternal level of knowledge on neonatal danger signs and to assess the associated factors among postnatal mothers attending at Woldia general hospital in the study area.

\section{Methods and materials}

Study area and period

Woldia town is located at $521 \mathrm{~km}$ away from the capital city, Addis Ababa. It is found at $2000 \mathrm{~m}$ above sea level with a temperature of $22{ }^{\circ} \mathrm{C}$. According to 2007 Ethiopian National population census [11]; the total population of the town is 75,496 people; among them, 38,167 are males and 37,279 are females. According to 2016 Woldia general hospital annual report; the mothers who had gotten PNC service were 2910. The study was conducted from January-May, 2017. The study employed institutional-based cross-sectional design including all 
postnatal mothers attending at the hospital during the study period. Mentally and physically incapable postnatal mothers to provide a response during data collection period were excluded.

\section{Study subjects}

During the study period, 197 postnatal mothers attending Woldia general hospital for PNC service were interviewed. All eligible postnatal mothers in selected study site were interviewed and neonatal danger signs were assessed through maternal recall.

\section{Data collection and analysis}

Pre-tested and interviewer administered questionnaire adopted from previous studies were employed to record mother's knowledge about neonatal danger signs, sociodemographic, and economic factors. The questionnaire was translated into the local language(Amharic) to make data collection process simple and translate back to the English language by translators who are perfect(good in English and Amharic language) to check the content validity of the original version. Three trained BSc degree holder health professionals conducted the data collection process.

The total number of correct spontaneous responses to 12 items (neonatal danger signs) with a minimum score of 0 and maximum of 12 was used to measure knowledge of mothers about neonatal danger signs. Accordingly, two categories were developed for neonatal danger sign. Spontaneous response is respondents naming of neonatal danger signs without giving the option of the respected signs. Mothers who mentioned at least six neonatal danger signs were considered as having good knowledge about neonatal danger signs and mothers who mentioned less than six neonatal danger signs were considered as having poor knowledge.

The completeness and consistency of the data were checked, cleaned and double entered to Epidemiological Information (EPI-INFO) software version 3.5.1 and analyzed by Statistical Package for Social Sciences (SPSS) software version 20. Frequencies, proportions, and summary statistics were used to describe the study population in relation to relevant variables and presented by using tables and graphs. A bivariate logistic regression model was fitted to identify factors, which were significant at $p<0.2$ and then entered into multivariate logistic regression model to identify independent factors those affected mother's knowledge about neonatal danger signs.

\section{Operational terms}

\section{Neonatal danger signs}

Are symptoms that complicate the lives of the neonate and happen during the neonatal period.

\section{Postnatal care}

Care given to a mother for a period of six weeks from the time of delivery using WHO standards contact time within one hour after birth, at 2-3 days, 6-7 days, and extra contacts for those LBW/mothers living with HIV.

\section{Knowledge}

State of awareness of mothers on neonatal danger signs; defined on the basis of the score (mean).

\section{Good knowledgeable}

Those mothers who are able to score above the mean of total knowledge based questions.

\section{Poor knowledgeable}

Those mothers who are able to score below the mean of total knowledge-based questions.

\section{Ethical considerations}

Ethical clearance was obtained from research review and ethical committee of Faculty of Health Science, Woldia University. Communication with the hospital medical director was made through formal letter obtained from Woldia University, Health Science Faculty. After explained the purpose and objective of the study, the researchers obtained written consent of mothers with their age greater than18years. Moreover, written consent was obtained from caretakers on behalf of those with age less than 18 years. Mothers were informed that their participation was on a voluntary basis, and the information obtained from them was kept confidential through no identifier was used.

\section{Results}

Social-demographic characteristics of the respondents

A total of 197 mothers were interviewed during data collection; of these, about $141(71.6 \%)$ are under 18-35 years old with the mean age of 23.9. Mothers who live in urban accounts $120(60.9 \%)$, while $77(39.1 \%)$ them were living in rural. Of the total interviewed mothers 163 $(82.7 \%)$ were married, and the majority $125(63.5 \%)$ were the housewife and 50(25.4\%) of them can't read and write. About 134 (69.0\%) of them are Orthodox Christian followers. Among the total mothers, 106(53.8\%) had less than three family size (Table 1 ).

\section{Antenatal and postnatal care utilizations of mothers}

Among 197 mothers, 172(87.3\%) of them had ANC follow-up at health institution; and about 13 (6.6\%), 38 (19.3\%) and 52(26.4\%) had 1st visit, 2nd visit, 3rd visit respectively, and $72(36.5 \%)$ of them had completed ANC visit. From total participants, only $122(61.9 \%)$ had gotten information about PNC followed. The majority of mothers, 99(50.3\%) got information from healthcare 
Table 1 Socio-demographic characteristics of mothers attending PNC at Woldia General Hospital, January-May, 2017

\begin{tabular}{|c|c|c|c|}
\hline Attributes & & $\mathrm{N}$ & $\%$ \\
\hline Age of mother's(years) & $<18$ & 22 & 11.2 \\
\hline & $18-35$ & 141 & 71.6 \\
\hline & $36-45$ & 33 & 16.8 \\
\hline & $>45$ & 1 & 0.5 \\
\hline Mother's residence & Urban & 120 & 60.9 \\
\hline & Rural & 77 & 39.1 \\
\hline Mother's marital status & Single & 26 & 13.2 \\
\hline & Married & 163 & 82.7 \\
\hline & Divorced & 6 & 3.0 \\
\hline & Widowed & 2 & 1.0 \\
\hline Mother's occupation & Housewife & 125 & 63.5 \\
\hline & Merchant & 20 & 10.2 \\
\hline & Gov't Employee & 31 & 15.7 \\
\hline & Student & 14 & 7.1 \\
\hline & Others & 7 & 3.6 \\
\hline Family's monthly income(birr) & $<500$ & 76 & 38.6 \\
\hline & $500-1000$ & 46 & 23.4 \\
\hline & $>1000$ & 75 & 38.1 \\
\hline Mother's educational status & Can't read and write & 50 & 25.4 \\
\hline & Can read and write & 29 & 14.7 \\
\hline & Grade 1-8 & 36 & 18.3 \\
\hline & Grade 9-10 & 37 & 18.8 \\
\hline & Grade 11-12 & 20 & 10.2 \\
\hline & Diploma \& above & 25 & 12.7 \\
\hline Mother's religion & Orthodox Christian & 134 & 68.0 \\
\hline & Muslim & 58 & 29.4 \\
\hline & Protestant & 4 & 2.0 \\
\hline & Catholic & 1 & 0.5 \\
\hline Mother's ethnicity & Amhara & 165 & 83.8 \\
\hline & Tigre & 19 & 9.6 \\
\hline & Afar & 12 & 6.1 \\
\hline & Others & 1 & 0.5 \\
\hline Family size & $1-3$ & 106 & 53.8 \\
\hline & $4-6$ & 73 & 37.1 \\
\hline & $>7$ & 18 & 9.1 \\
\hline Husband's education status & Can't read and write & 28 & 14.2 \\
\hline & Can read and write & 38 & 19.3 \\
\hline & Grade 1-8 & 31 & 15.7 \\
\hline & Grade 9-10 & 34 & 17.3 \\
\hline & Grade 11-12 & 20 & 10.2 \\
\hline & Diploma \& above & 46 & 23.4 \\
\hline Distance to health institution & $<5 \mathrm{~km}$ & 86 & 43.7 \\
\hline & $5-20 \mathrm{~km}$ & 63 & 32.0 \\
\hline & $>20 \mathrm{~km}$ & 48 & 24.4 \\
\hline
\end{tabular}

providers. Most of the study participants 127(64.0\%) don't know the right postnatal period (PNP) follow-up time. Of the total mothers, 107(54.3\%) of them did not know the PNP is a danger time for mothers and neonates. The reason to attend current PNC was 52(26.4\%) excessive bleeding, 41(20.8\%) neonatal infection, $39(19.8 \%)$ unable to breastfeeding. Out of the total respondents, 32(16.2\%) delivered their current baby at home (Table 2).

\section{Sources of information for mothers about neonatal danger signs}

The study revealed that about $105(53 \%)$ of mothers attending PNC at Woldia general hospital had gotten information about neonatal danger sign from health providers, while $33(16.8 \%)$ of mothers had gotten information from health extension workers (fig. 1).

\section{Maternal level of knowledge on neonatal danger signs}

The scoring of neonatal danger signs was evaluated and scored. For mothers who were able to identify less than six neonatal danger signs were classified as having a low level of knowledge and those who scored more than six were classified as having a good level of knowledge on neonatal danger signs. The majority of mothers, $174(88.3 \%)$ had a low level of knowledge. Twenty-three $(11.7 \%)$ of mothers had good levels of knowledge about neonatal danger sign $(95 \%$ CI $7.6,16.3)$. The most commonly reported source of information was health-care providers (53\%) (Fig. 2).

\section{Mother's recognition of neonatal danger signs}

The hotness of the body was the commonly recognized neonatal danger sign by $106(53.8 \%)$ postnatal mothers. Out of 197 mothers, 67(34\%), 60(30.5\%), 56(28.4\%), $44(22 \%), \quad 43(21.8 \%), \quad 40(20.3 \%), \quad 35(17.8 \%), \quad 22(11.2 \%)$, $21(10.7 \%), \quad 20(10.2 \%), \quad 17(8.6 \%)$ identified unable to breastfeeding, convulsion, lethargy, difficulty in breathing, persistent vomiting, diarrhea, coldness, umbilical bleeding, abdominal distention, and yellowness of palms and soles as newborn danger signs, respectively(Fig. 3).

\section{Factors associated with maternal level of knowledge about neonatal danger signs}

After controlling for socio-demographic, economic, and maternal factors; age of mother's, mother educational status, mothers marital status, Mother's occupation, husband educational status, attending ANC, Mother's residence, Distance to health institution and having neonatal danger signs information to mother were the factors that significantly affect maternal levels of knowledge.

Women whose age $18-35$ years were $33 \%(\mathrm{AOR}=1.33$, 95\% CI: 1.99-3.08) more likely to be knowledgeable as compared to mothers who are $<18$ years old. Women who are widowed had two times less likely $(\mathrm{AOR}=2.50$, 95\% CI: $0.29-4.31)$ to identify at least six neonatal danger signs. Mothers who are diploma and above 
Table 2 Antenatal and postnatal care utilization of mothers attending PNC at Woldia General Hospital, January-May, 2017

\begin{tabular}{|c|c|c|c|}
\hline Attributes & & $\mathrm{N}$ & $\%$ \\
\hline \multirow[t]{2}{*}{ Do you know ANC follow up time? } & Yes & 69 & 35.0 \\
\hline & No & 128 & 65.0 \\
\hline \multirow[t]{2}{*}{ Did you attend ANC? } & Yes & 172 & 87.3 \\
\hline & No & 25 & 12.7 \\
\hline \multirow[t]{4}{*}{ How many ANC visit did you attend? } & 1 Visit & 10 & 5.1 \\
\hline & 2 Visit & 38 & 19.3 \\
\hline & 3 Visit & 52 & 26.4 \\
\hline & 4 Visit & 72 & 36.5 \\
\hline \multirow{2}{*}{$\begin{array}{l}\text { Did you get information about } \\
\text { postnatal service? }\end{array}$} & Yes & 122 & 61.9 \\
\hline & No & 75 & 38.1 \\
\hline \multirow{5}{*}{$\begin{array}{l}\text { What is your source of information } \\
\text { about PNC Service? }^{\text {a }}\end{array}$} & Health Provider & 99 & 50.3 \\
\hline & $\begin{array}{l}\text { Health Extension } \\
\text { workers }\end{array}$ & 17 & 8.6 \\
\hline & $\begin{array}{l}\text { Community } \\
\text { Conversation }\end{array}$ & 1 & 0.5 \\
\hline & Media(TV, Radio) & 5 & 2.5 \\
\hline & $\begin{array}{l}\text { Traditional Birth } \\
\text { Attendant }\end{array}$ & 0 & 0 \\
\hline \multirow[t]{4}{*}{ Knowing when PNC starts } & $\begin{array}{l}\text { On the date of } \\
\text { delivery (1-6 h) }\end{array}$ & 41 & 20.8 \\
\hline & 6 h-6 days & 18 & 9.1 \\
\hline & $6-7$ days & 5 & 2.5 \\
\hline & $>7$ days & 7 & 3.6 \\
\hline \multirow{2}{*}{$\begin{array}{l}\text { Knowing PNP is danger time for } \\
\text { mothers \& neonates }\end{array}$} & Yes & 90 & 45.7 \\
\hline & No & 107 & 54.3 \\
\hline \multirow[t]{2}{*}{ Do you know danger signs of PNP? } & Yes & 95 & 48.2 \\
\hline & No & 24 & 12.2 \\
\hline \multirow{5}{*}{$\begin{array}{l}\text { Types of PNP Danger signs for } \\
\text { mothers and neonates }\end{array}$} & Excessive bleeding & 100 & 50.8 \\
\hline & Neonatal infections & 64 & 32.5 \\
\hline & Unable to breastfeed & 68 & 34.5 \\
\hline & Vomiting & 61 & 31.0 \\
\hline & Others & 16 & 8.1 \\
\hline \multirow{4}{*}{$\begin{array}{l}\text { Reasons to attend current PNC } \\
\text { service }^{a}\end{array}$} & Excessive bleeding & 41 & 20.8 \\
\hline & Neonate infections & 52 & 26.4 \\
\hline & $\begin{array}{l}\text { Unable to breast } \\
\text { feed }\end{array}$ & 39 & 19.8 \\
\hline & Others & 66 & 33.5 \\
\hline \multirow{6}{*}{$\begin{array}{l}\text { What education did you get during } \\
\text { PNC attending time? }{ }^{\text {a }}\end{array}$} & Personal hygiene & 128 & 65.0 \\
\hline & Immunization & 136 & 69.0 \\
\hline & Family planning & 135 & 68.5 \\
\hline & Breast feeding & 109 & 55.3 \\
\hline & Neonatal infection & 92 & 46.7 \\
\hline & Care to ill neonates & 66 & 33.5 \\
\hline \multirow{2}{*}{$\begin{array}{l}\text { Did you get the education about your } \\
\text { neonate danger signs during PNC? }\end{array}$} & Yes & 105 & 53.3 \\
\hline & No & 92 & 46.7 \\
\hline
\end{tabular}

Table 2 Antenatal and postnatal care utilization of mothers attending PNC at Woldia General Hospital, January-May, 2017 (Continued)

\begin{tabular}{|c|c|c|c|}
\hline Attributes & & $\mathrm{N}$ & $\%$ \\
\hline \multirow[t]{7}{*}{$\begin{array}{l}\text { What education did you get about } \\
\text { your neonate during PNC? }{ }^{a}\end{array}$} & $\begin{array}{l}\text { The advantage of } \\
\text { breastfeeding }\end{array}$ & 91 & 46.2 \\
\hline & Cord care & 62 & 31.5 \\
\hline & Eye care & 54 & 27.4 \\
\hline & Thermoregulation & 54 & 27.4 \\
\hline & $\begin{array}{l}\text { Different } \\
\text { immunization }\end{array}$ & 63 & 32.0 \\
\hline & $\begin{array}{l}\text { About neonatal } \\
\text { danger signs }\end{array}$ & 53 & 26.9 \\
\hline & Others & 4 & 2.0 \\
\hline \multirow{3}{*}{$\begin{array}{l}\text { Where did you deliver your current } \\
\text { baby? }\end{array}$} & Home & 32 & 16.2 \\
\hline & Hospital & 149 & 75.6 \\
\hline & Health Center & 16 & 8.1 \\
\hline \multirow[t]{3}{*}{ How did you deliver? } & $\begin{array}{l}\text { Spontaneous vertex } \\
\text { delivery }\end{array}$ & 132 & 67.0 \\
\hline & Cesarean section & 54 & 27.4 \\
\hline & Instrumental & 11 & 5.6 \\
\hline
\end{tabular}

${ }^{\mathrm{a}}$ Multiple responses of respondents

education level were three times $(\mathrm{AOR}=3.48,95 \% \mathrm{CI}$ : 1.57-8.72), and more than three times (AOR $=3.05,95 \%$ CI: $1.83-6.90)$ to be knowledgeable about neonatal danger signs as compared to mothers who can't read and write, respectively. Similarly, mothers whose husbands are preparatory school education $(\mathrm{AOR}=4.92, \quad 95 \%$ CI:1.29-12.81) were nearly four times more likely to mention at least six neonatal danger signs as compared to husbands who can't read and write. Furthermore, mothers who attended ANC during the last pregnancy were two times more likely to head knowledge $(\mathrm{AOR}=2.88,95 \% \mathrm{CI} 1.15,4.85)$ about neonatal danger signs as compared to those who did not follow. Mothers who live in the urban area were $22 \%$ more likely to have knowledge (AOR $=0.78,95 \% \mathrm{CI}$ : 0.47-1.65) about neonatal danger signs as compared to those living in rural area. Likewise, mothers who had got information about danger signs increased their knowledge about neonatal danger signs by 3 times (AOR $=3.48,95 \%$ CI 1.40-9.49) (Table 3).

\section{Discussion}

This institutional based cross-sectional study has assessed the levels of maternal knowledge and the associated factors on neonatal danger signs among mothers attending postnatal care at Woldia general hospital. Reduction of neonatal and infant mortality to an acceptable level is impossible without good maternal knowledge level regarding neonatal danger signs. This is because of 


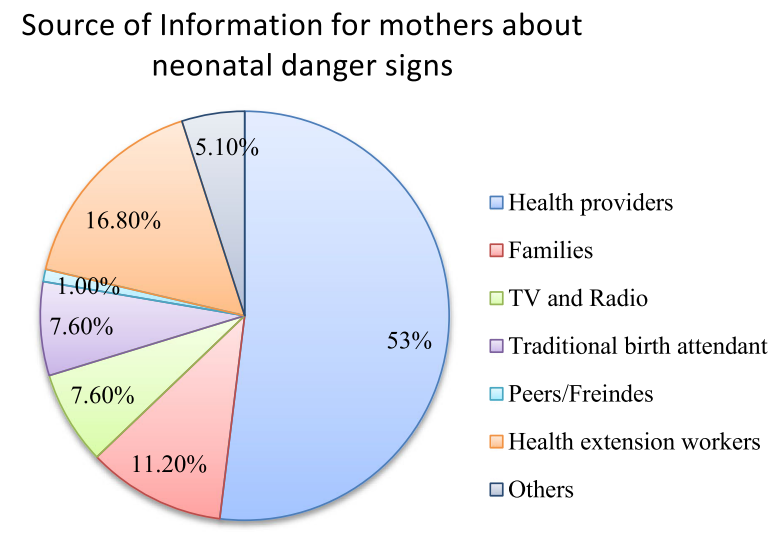

Fig. 1 Source of information for mothers on neonatal danger signs

the fact that, these danger signs are the entry point to provide comprehensive neonatal health care [3].

In this study, the prevalence of mothers' good knowledge (mothers who mentioned at least six and above neonatal danger sign) was found to be $11.67 \%$. The finding reported that most mothers have a very poor level of knowledge 174(88.3\%) about neonatal danger signs. This is slightly higher than the finding reported from Kenya that $84.5 \%$ of the maternal level of knowledge is poor to identify at least three neonatal danger signs from eight mentioned danger signs [8]. Similarly, low maternal levels of knowledge to identify at least one neonatal danger signs was reported from Southwestern Rural Uganda [2]. This may be due to information on danger sign was not adequately disseminated to mothers both during antenatal and PNC period [8]. From total PNC attending women, $74.7 \%$ of respondents had formal education

\section{Maternal knoledge on neonatal danger signs}

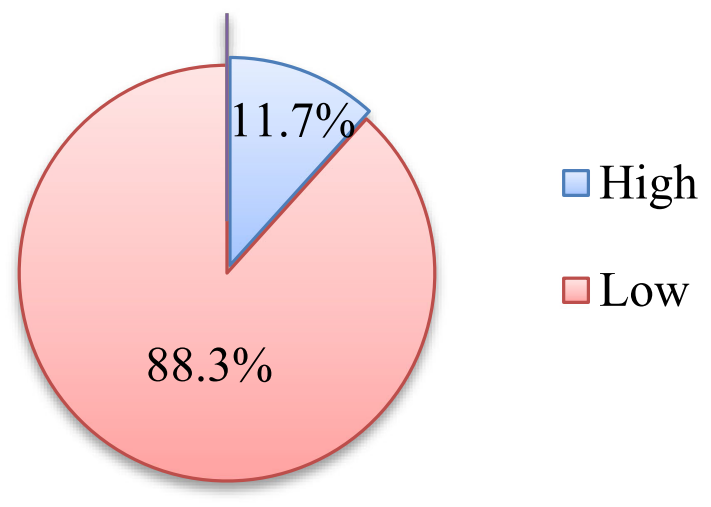

Fig. 2 Maternal level of Knowledge on Neonatal danger signs

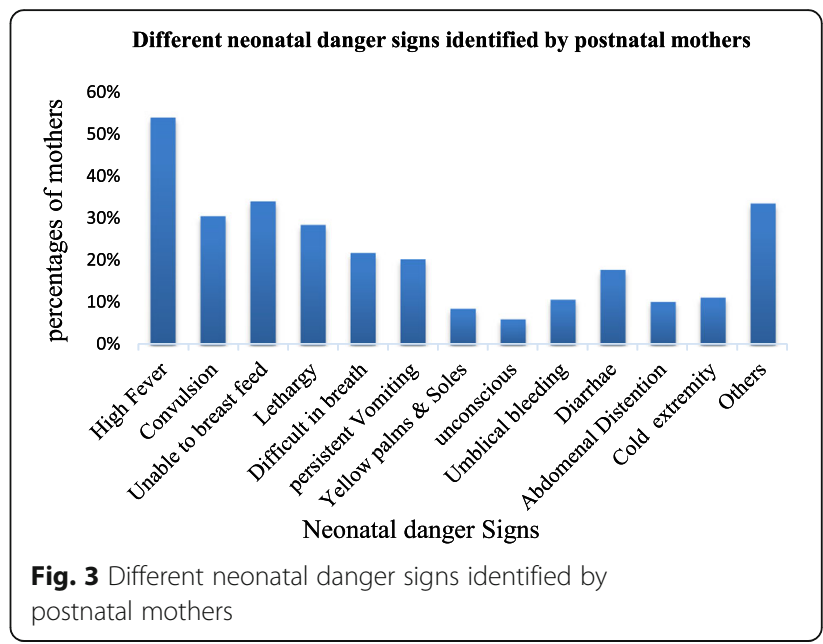

from elementary to higher education. Similarly, a study conducted at Addis Ababa reported that mothers attending PNC (35\%) have primary school certificate [14]. Maternal education plays a major role in the understanding of neonatal danger signs. In this study mothers who had diploma certificate and above were three times (AOR $=3.48,95 \%$ CI: $1.57-8.72)$ more likely to be knowledgeable about neonatal danger signs as compared to mothers who can't read and write. This is in line with neonatal danger signs knowledge level reported from North West of Ethiopia that mothers having secondary and above educational level increased the odds of their knowledge by nearly three times [3]. The possible justification for this could be educated mothers attain knowledge about the neonatal disease and maternal health through their academic life.

The distance of mothers from health institutions can also determine for appropriate ANC and PNC service utilization; our study revealed that $24.4 \%$ of mothers travel $>20 \mathrm{~km}$ to get PNC service at Woldia general hospital. Mothers who live in the urban area were $22 \%$ more likely to have knowledge (AOR $=0.78,95 \% \mathrm{CI}$ : $0.47-1.65$ ) about neonatal danger signs as compared to those living in rural area. In contrast to this, the study reported from Southwestern rural Uganda revealed that no association between mothers residence and levels of knowledge on neonatal danger signs [2]. This may be due to those mothers who live far away from health institutions would not have access to ANC and PNC service and would have low access to information about neonatal danger signs.

In our study about $32(16.2 \%)$ of women delivered at home (outside the formal health system). In contrast to our report, in India, about 200(70.5\%) deliveries take place at home attended by untrained personnel [15]. This difference may be due to study area difference that our study was an institution based whereas Indian study 
Table 3 Factors associated with mother's knowledge on neonatal danger signs at Woldia general hospital, January-May, 2017

\begin{tabular}{|c|c|c|c|c|c|}
\hline \multirow[t]{2}{*}{ Characteristics } & & \multicolumn{2}{|c|}{ Knowledge on neonatal danger sign } & \multirow{2}{*}{$\begin{array}{l}\text { Crude OR (95\% } \\
\mathrm{Cl})\end{array}$} & \multirow{2}{*}{$\begin{array}{l}\text { Adjusted OR (95\% } \\
\text { Cl) }\end{array}$} \\
\hline & & Good(N) & Poor(N) & & \\
\hline \multirow[t]{4}{*}{ Age of mother's(year) } & $<18$ & 1 & 21 & 1 & 1 \\
\hline & $18-35$ & 20 & 121 & $1.62(1.41-2.96)^{*}$ & $1.50(0.19-2.41)$ \\
\hline & $36-45$ & 2 & 31 & $3.46(2.30-5.71)^{*}$ & $1.33(1.99-3.08)^{* *}$ \\
\hline & $>45$ & 0 & 1 & $0.84(0.41-3.16)^{*}$ & $0.75(0.57-1.95)$ \\
\hline \multirow[t]{4}{*}{ Marital status } & Married & 19 & 144 & 1 & 1 \\
\hline & Single & 3 & 23 & $1.80(1.54-6.10)$ & $1.60(0.39-4.32)$ \\
\hline & Divorce & 0 & 6 & $2.88(0.46-4.31) *$ & $1.33(0.89-4.08)^{* *}$ \\
\hline & Widowed & 1 & 1 & $3.94(0.31-4.26)^{*}$ & $2.50(0.29-4.31)^{* *}$ \\
\hline \multirow[t]{6}{*}{ Mother education } & Can't read and write & 1 & 49 & 1 & 1 \\
\hline & Can read and write & 4 & 25 & $10.86(2.50-75.43)^{*}$ & $4.50(2.18-7.51)$ \\
\hline & Grade 1-8 & 2 & 34 & $9.83(2.61-55.65)^{*}$ & $5.33(2.99-6.08)$ \\
\hline & Grade 9-10 & 7 & 30 & $4.54(0.31-5.26)$ & $7.72(1.39-63.46)^{* *}$ \\
\hline & Grade 11-12 & 2 & 18 & $6.18(2.42-11.51)$ & $3.05(1.83-6.90)^{* *}$ \\
\hline & Diploma \& above & 7 & 18 & $10.2(5.43-23.01)^{*}$ & $3.48(1.57-8.72)^{* *}$ \\
\hline \multirow[t]{5}{*}{ Mother's occupation } & Housewife & 12 & 113 & 1 & 1 \\
\hline & Merchant & 2 & 18 & $9.76(3.50-45.23)$ & $4.05(2.26-8.37)$ \\
\hline & Gov't Employee & 6 & 25 & $10.83(2.61-95.74)^{*}$ & $5.57(2.82-9.81)^{* *}$ \\
\hline & Student & 2 & 12 & $9.83(1.38-83.27)^{*}$ & $3.48(0.78-5.89)^{* *}$ \\
\hline & Others & 1 & 6 & $3.11(1.26,8.48)$ & $1.33(0.28,7.18)$ \\
\hline \multirow[t]{6}{*}{ Husband's education } & Can't read and write & 1 & 27 & 1 & 1 \\
\hline & Can read and write & 3 & 35 & $2.52(0.81-4.85)^{*}$ & $1.62(0.91-2.86)$ \\
\hline & Grade 1-8 & 1 & 30 & $2.66(1.40-4.81)^{*}$ & $0.96(0.40-1.81)$ \\
\hline & Grade 9-10 & 5 & 29 & $2.88(0.37-4.65)$ & $0.78(0.47-1.55)$ \\
\hline & Grade 11-12 & 3 & 17 & $9.73(3.44-27.96)$ & $4.92(1.29-12.81)^{* *}$ \\
\hline & Diploma \& above & 10 & 36 & $13.8(4.12-44.54)^{*}$ & $4.81(1.43-12.46)$ \\
\hline \multirow[t]{2}{*}{ ANC } & Yes & 22 & 150 & $6.71(4.27-17.49)^{*}$ & $2.88(1.15,4.85)^{* *}$ \\
\hline & No & 1 & 24 & 1 & \\
\hline \multirow[t]{3}{*}{ Place of delivery } & Home & 1 & 31 & $0.28(0.23-2.57)$ & \\
\hline & Hospital & 19 & 130 & $2.18(1.44-3.63)^{*}$ & \\
\hline & Health Center & 3 & 13 & 1 & 1 \\
\hline \multirow[t]{2}{*}{ Mother's residence } & Urban & 19 & 101 & $2.77(1.55,4.93)^{*}$ & $0.78(0.47-1.65)^{* *}$ \\
\hline & Rural & 4 & 73 & 1 & 1 \\
\hline \multirow[t]{3}{*}{ Distance to health institution } & $<5 \mathrm{~km}$ & 14 & 72 & $5.66(2.82-7.82)$ & $2.72(0.46-3.85)$ \\
\hline & $5-20 \mathrm{~km}$ & 7 & 56 & $1.67(0.98-2.49)^{*}$ & $0.46(0.30-0.81)^{* *}$ \\
\hline & $>20 \mathrm{~km}$ & 2 & 46 & $1.33(0.88-7.89)^{*}$ & $0.78(0.47-1.75)^{* *}$ \\
\hline \multirow[t]{2}{*}{ Danger signs information to mother } & Yes & 20 & 85 & $7.77(3.96-16.07)$ & $3.48(1.40-9.49)^{* *}$ \\
\hline & No & 3 & 89 & 1 & 1 \\
\hline
\end{tabular}

*P-value $<0.2 ; * *$-value $<0.05$

was community-based. Regarding associated factors; maternal knowledge, mother's age, educational status, marital status, occupation, attending ANC, residence, distance to health institution, danger signs information to the mother, husband educational status were significantly affect maternal levels of knowledge to identify at least six neonatal danger signs in our study. Similarly, the study done in Kenya reported that mother's education level, PNC accompaniment by Spouse, danger signs information to mother were factors positively associated with better knowledge on neonatal danger sign [8]. 


\section{Conclusion}

Investigators agreed that mothers can have a great role in caring new born baby and identifying neonatal danger signs. The findings of our study revealed that there is a poor understanding of neonatal danger signs 174 (88.3\%). Even participant's record has the highest number of ANC attendance $(87.3 \%)$ and institutional deliveries (83.7\%), the existing knowledge gap in this key area of neonatal danger signs affect the success of childcare services; this needs to increase educational efforts aimed for all pregnant and delivered women in the hospital as well as in the community.

\section{Abbreviations}

ANC: Antenatal care; AOR: Adjusted odds ratio; Cl: Confidence interval; EDHS: Ethiopian Demographic and Health Survey; EPI-INFO: Epidemiological Information software; HIV: Human immunodeficiency virus; LBW: Low birth weight; MDG: Millennium Development Goal; PNC: Postnatal care; PNP: Postnatal period; SPSS: Statistical package for social sciences; WHO: World health organization

\section{Acknowledgements}

Our sincere gratitude goes to Woldia University, Faculty of Health Science for all supports. We would like to acknowledge the study participants for their participation and without them, the research would not realize.

\section{Competing interests}

The authors declare that they have no competing interests.

\section{Funding}

The authors declared that this study has received no financial support.

\section{Availability of data and materials.}

The raw dataset is available from the corresponding author on reasonable request.

\section{Authors' contributions.}

MMJ, ETB, HBM, DMG, and AET participated in the study design, implementation of the study, and data collections. MAR designed the study, performed the statistical analysis and drafted the manuscript for publication. All authors contributed to the data analysis, read and approved the final manuscript.

\section{Consent for publication.}

Not applicable.

\section{Ethics approval and consent to participate.}

Ethical clearance was obtained from research and an ethical review committee of Faculty of Health Science, Woldia University. The official letter that explains the objectives, rationale and expected outcomes of the study was written to the zonal health department. Permission letter was obtained from Zone health department and medical director of the hospital. Information was collected after obtaining verbal consent from each postnatal mother. Respondents were also being informed that they can refuse or discontinue participation at any time they want. All study participants were labeled using a unique code instead of names to ensure confidentiality.

\section{Publisher's Note}

Springer Nature remains neutral with regard to jurisdictional claims in published maps and institutional affiliations.

\section{Author details}

${ }^{1}$ Department of Midwifery, Faculty of Health Science, Woldia University, P.O.Box 400, Woldia, Ethiopia. ${ }^{2}$ Department of Medical Laboratory Science, Faculty of Health Science, Woldia University, P.O.Box 400, Woldia, Ethiopia.
Received: 30 June 2017 Accepted: 9 January 2018

Published online: 21 March 2018

\section{References}

1. Aijaz N, Huda N, Kausar S. Disease burden of NICU at a tertiary care hospital, Karachi. Journal of the Dow University of Health Sciences Karachi. 2012;6(1):35.

2. Sandberg J, Odberg PK, Asp G, Kabakyenga J, Agardh A. Inadequate knowledge of neonatal danger signs among recently delivered women in southwestern rural Uganda: a community survey. PLoS One. 2014;9(5):e97253.

3. Nigatu GS, Worku GA, Dadi FA. Level of mother's knowledge about neonatal danger signs and associated factors in north west of Ethiopia: a community based study. BMC Res Notes. 2015;8(309)

4. Assefa N, Lakew Y, Belay B, Kedir H, Zelalem D, Baraki N, et al. Neonatal mortality and causes of death in Kersa health and demographic surveillance system (Kersa HDSS), Ethiopia, 2008-2013. Matern Health, Neonatol, and Perinatology 2017;2:7.

5. Bogale W, Mulualem G. New born care training participants manual. Addis Ababa,Ethiopia: FMOH; 2012

6. Mekonnen Y, Tensou B, Telake SD, Degefie T, Bekele A. Neonatal mortality in Ethiopia: trends and determinants. BMC Public Health. 2013;13(483)

7. Joy EL, Kate K, Christabel EL, Simon C, Dip MS. 3.6 Million Neonatal: Deaths-What Is Progressing and What Is Not?Seminar in Perinatology. Elsevier. 2010;34:386.

8. Kibaru EG, Otara AM. Knowledge Of neonatal danger signs among mothers attending well baby clinic in Nakuru Central District, Kenya: cross sectional descriptive study. BMC Res Notes. 2016;9(1):481.

9. Mengesha HG, Sahle BW. Cause of neonatal deaths in northern Ethiopia: a prospective cohort study. BMC Public Health. 2017;17(62)

10. Okawa S, Ansah EK, Nanishi K, Enuameh Y, Shibanuma A, Kikuchi K, et al. High incidence of neonatal danger signs and its implications for postnatal Care in Ghana: a cross-sectional study. PLoS One. 2015;10(6):e0130712.

11. Central Statistical Agency[CSA-Ethiopia], and ICF. Ethiopia Demographic and Health Survey: Key Indicators Report. Addis Ababa,Ethiopia, and Rockville, Maryland, USA. CSA and ICF: FEDERAL DEMOCRATIC REPUBLIC OF ETHIOPIA; 2016.

12. Dongre AR, Deshmukh PR, Garg BS. Awareness and health care seeking for newborn danger signs among mothers in peri-urban Wardha. Indian J Pediatr. 2009;76(7):691-3.

13. Choi Y, ETS A, Mannan I, Rahman MS, Bari S, Darmstadt LG, et al. can mothers recognize neonatal illness correctly? Comparison of maternal report and assessment by community health workers in rural angladesh. Trop Med Int Health. 2010;15(6):753.

14. Chewaka L. Preventable causes of neonatal mortality and associated factors among neonates admitted to neonatal intensive care units of Addis Ababa governmental hospitals from 2011-2015 GC: a retrospective study [master]. Addis Ababa: Addis Ababa University; 2016.

15. Shally A, Tuhina V, Monica A. Danger Signs of neonatal illnesses: perceptions of caregivers and health workers in northern India. Bull World Health Organ. 2006;84(10):826.
Submit your next manuscript to BioMed Central and we will help you at every step:

- We accept pre-submission inquiries

- Our selector tool helps you to find the most relevant journal

- We provide round the clock customer support

- Convenient online submission

- Thorough peer review

- Inclusion in PubMed and all major indexing services

- Maximum visibility for your research

Submit your manuscript at www.biomedcentral.com/submit
C Biomed Central 